\title{
Kernos
}

Revue internationale et pluridisciplinaire de religion grecque antique

$10 \mid 1997$

Varia

\section{J. ADHÉMAR, Influences antiques dans l'art du Moyen} âge français

\section{Isabelle Lecocq}

\section{OpenEdition}

Journals

\section{Édition électronique}

URL : http://journals.openedition.org/kernos/678

DOI : $10.4000 /$ kernos. 678

ISSN : 2034-7871

\section{Éditeur}

Centre international d'étude de la religion grecque antique

\section{Édition imprimée}

Date de publication : 1 janvier 1997

Pagination : 339-340

ISSN : 0776-3824

\section{Référence électronique}

Isabelle Lecocq, « J. ADHÉmAR, Influences antiques dans l'art du Moyen âge français », Kernos [En ligne], 10 | 1997, mis en ligne le 12 avril 2011, consulté le 23 septembre 2020. URL : http:// journals.openedition.org/kernos/678; DOI : https://doi.org/10.4000/kernos.678 
Et le mythe à Rome ? Encore une question difficile, à laquelle M. BEARD entreprend d'apporter quelques éléments de réponse sur le ton de la provocation, consciente et assumée, autour de la figure monstrueuse de l'Hercule Farnèse qui ornait les thermes de Caracalla. Si le mythe est bien, comme elle l'entend, une «stratégie culturelle » qui permet de discuter la vérité, alors cet Hercule aux bains appartient au «mythe de la vérité des bains », activité typiquement romaine, et devait interpeller le baigneur sur sa virilité, sur le ridicule aussi, tout autant que sur la grécité sans cesse « au cœur de toute chose romaine ». Le pari est intéressant, mais pas entièrement convaincant. Sans doute l'hellénocentrisme est-il encore trop prégnant!

Les deux dernières contributions du volume étudient respectivement la mythologie à l'âge " baroque » et les nouveaux territoires du mythe au XVIII ${ }^{\mathrm{e}}$ siècle. Il s'agit tout d'abord de comprendre comment une religion toute-puissante et exclusive comme la religion catholique a pu accepter une mythologie qui lui est étrangère. Dans le conflit d'intérêt posé par la " gestion » de l'héritage antique, la Contre-Réforme a tranché avec prudence et favorisé l'« humanisme dévôt ». Les scrupules éventuels ont été calmés par « la mise en perspective historique de la mythologie comme stade primitif de l'humanité » et par les efforts consentis pour en faire un langage abstrait. Elle est peu à peu devenue une agréable convention dépourvue de tout danger (J. THuiluER). Mais les artistes vont progressivement se libérer des traditions héritées de la Renaissance pour favoriser les apports de l'archéologie, conjugués à l'inspiration littéraire, dans la représentation des thèmes antiques. Le souci d'une connaissance raisonnée destinée à restaurer «scientifiquement » les sculptures va les guider. Pier $\mathrm{L}$. Ghezzi, le comte de Caylus et Winckelmann constituent autant d'étapes de ce nouveau regard (J. RASPI-SERRA).

Un très beau volume, aux larges perspectives et aux illustrations remarquables.

Vinciane PIRENNE-DELFORGE

(Université de Liège)

Jean ADHÉmar, Influences antiques dans l'art du Moyen âge frangais. Préface de Léon Pressouyre, Édition du Comité des Travaux Historiques et Scientifiques, 1996, 463 p., 127 fig. (Format 21).

Cet ouvrage est en fait la réédition de la thèse de doctorat de l'A., mort en 1987, archiviste-paléographe, élève de Focillon et disciple d'Ady Warburg, Influences antiques dans l'art du Moyen âge français. Recherches sur les sources et les thèmes d'inspiration, London, The Warburg Institute, 1939. Cette thèse devait clore de vieux débats en démontrant principalement que l'influence antique n'avait cessé de s'exercer pendant les « siècles obscurs » du Moyen âge.

L'économie générale de l'ouvrage repose sur ce présupposé : « une "Renaissance" au sens d'imitation volontaire et consciente de l'antique n'est possible et viable qu'à deux conditions : l'amour des lettres classiques connues d'après les originaux et un vif sentiment de la beauté des témoins matériels ». L'A. retrace donc d'abord l'histoire des études classiques et de l'humanisme au Moyen âge qui connaissent une floraison brillante sous Charlemagne ainsi qu'aux $\mathrm{XI}^{\mathrm{e}}$ et $\mathrm{XII}^{\mathrm{e}}$ siècles. Cet humanisme est nourri tantôt par la lecture assidue de manuscrits d'auteurs classiques préservés dans les bibliothèques monastiques, tantôt par celle d'adaptations très éloignées de véritables traductions. L'A. ne s'attarde ni sur le préhumanisme du $\mathrm{XV}^{\mathrm{e}}$ siècle ni sur les signes 
d'une nouvelle renaissance qui l'accompagne, importés directement d'Italie. Dans une seconde partie, l'A. interroge de nombreux textes du Moyen âge pour connaître le sort des vestiges antiques contemporains conservés dans les diverses régions de France. Ces textes révèlent l'attrait des gens d'alors pour les ruines (temples, amphithéâtres, aqueducs, murs des villes), les sculptures (sarcophages, statues, cippes) et les objets d'art antiques qui les entourent. Ils dévoilent aussi les raisons de cet engouement et les variations d'intensité de cet intérêt depuis l'époque de Grégoire de Tours jusqu'à celle de Jean Fouquet. Dans une troisième et dernière partie, l'A. présente enfin les influences antiques dans l'art du Moyen âge en les rapportant à leur source. La moisson est importante pour les périodes carolingienne et romane, mais très faible pour l'époque gothique, au début de laquelle on remarque pourtant quelques efforts isolés et sans lendemain, ceux du "Maître des Figures Antiques " et de son élève, Villar de Honnecourt.

Les quelques coquilles qui subsistent dans le texte témoignent de l'absence de remise à jour. Le travail n'en souffre pas : l'argumentation reste convaincante et exemplaire. Il a ouvert la voie à des recherches plus ciblées dont les résultats sont présentés lors d'expositions qui font date : pour la renaissance carolingienne, Karl der Grosse (Aix-la-Chapelle, 1965), pour les efforts isolés à l'aube du gothique, The Year 1200 (New York, 1970), pour l'humanisme du $\mathrm{xv}^{\mathrm{e}}$ siècle, Les fastes du gotbique (Paris, 1980). Il convient aussi de mentionner les recherches d'E. Panofsky, Renaissance and Renascences in Western Art, publiées en 1960; il s'interroge sur l'opportunité de distinguer la Renaissance, phénomène unique, et les renouveaux médiévaux qui constitueraient autant de renaissances.

Isabelle LECOCQ

(Université de Liège)

Philippe DaIN, Mythographe du Vatican I. Traduction et commentaire, Besançon-Paris, 1995. 1 vol. 15, $5 \times 24 \mathrm{~cm}$, XIX+244 p. (Annales Littéraires de l'Université de Basançon, 579. Centre de Recherches d'Histoire Ancienne, 151. Institut Félix Gaffiot, 12. Lire les polythéismes, 5). ISBN : 2-251-60579-7.

Nul doute que, dans le domaine francophone, 1995 pourra être considéré comme une année faste pour le Premier Mythograpbe du Vatican, puisque deux traductions françaises de cet ouvrage curieux ont vu le jour presque simultanément. L'une, accompagnée du texte latin, établi par N. ZORZETTI, est due à J. BERLIOZ et a paru dans la Collection des Universités de France. L'autre, sans le texte latin, est l'ouvre de Ph. DAIN et est publiée dans une collection diffusée aussi par la Maison d'éditions « Les Belles Lettres ». Les spécialistes, mais aussi les lecteurs moins versés dans le domaine de la mythologie gréco-romaine, peuvent se réjouir d'autant plus que les deux traductions sont accompagnées d'abondantes notes destinées à fournir toutes les explications utiles à l'intelligence d'un texte rempli d'allusions.

C'est en 1831 qu'Angelo MaI publia, sous l'appellation de Mytbograpbi Vaticani, les textes de trois auteurs dont il venait de découvrir les manuscrits à la Bibliothèque Vaticane. Ces traités de mythologie offrent un choix de mythes gréco-latins, repris à des mythographes antérieurs, comme Fulgence, auxquels sont venus se greffer des récits issus de la tradition romaine. Nommés Mythographes I, II et III d'après l'ordre chronologique supposé d'âge ou de publication, - les deux premiers écrivains semblent 